양동훈 · 박상욱 · 문형철 · 유경완 - 은서준 · 문승기 · 박철민 · 조신형

\title{
Spontaneous Common Bile Duct Perforation Treated with Placement of Metal Stent
}

\author{
Dong Hoon Yang, Sang Wook Park, Hyeung Chul Moon, Kyoung Wan You, Seo Joon Eun, Seung Ki Moon, \\ Choel Min Bak, Shin Hyoung Jo \\ Divison of Gastroenterology, Department of Internal Medicine, Kwangju Christian Hospital, Kwangju, Korea
}

Perforation of the biliary tree mostly results from injury to the bile duct during surgery or procedures such as endoscopic retrograde cholangiopancreatography (ERCP) and spontaneous bile duct perforation is rare in adults. As the clinical picture varies, early diagnosis and treatment of spontaneous biliary peritonitis is difficult. A 52-year-old male patient presented with abdominal pain and intractable ascites. He already experienced severe abdominal pain 2 months ago and underwent percutaneous pigtail drainage for the ascites at nearby hospital. ERCP showed large filling defect with leakage of contrast media from the mid common bile duct (CBD) into the peritoneal cavity. We performed endoscopic sphincterotomy and extracted CBD stones with basket and balloon catheter. Then fully covered self expandable metal stent was placed in CBD. After the procedure, the symptom was improved and the amount of pigtail drainage from abdominal cavity was dramatically decreased. 6 weeks later, removing the metal stent, there was no more leakage of contrast media into peritoneal cavity. We report a very rare case of spontaneous bile leakage which was successfully managed with placement of metal stent.

Korean J Pancreas Biliary Tract 2016;21(4):222-227

Keywords: Biliary perforation, Common bile duct, Endoscopic retrograde cholangiopancreatography, Self expandable metallic stent, Ascites

\begin{abstract}
Received Jun. 21, 2016
Revised Jul. 25, 2016

Accepted Jul. 28, 2016
\end{abstract}

Corresponding author: Sang Wook Park Divison of Gastroenterology, Department of Internal Medicine, Kwangju Christian Hospital, 37 Yangnimro, Nam-gu, kwangju 61661, Korea

Tel. +82-62-650-5023 Fax. +82-62-650-5277

E-mail; kch20491@naver.com

This is an Open Access article distributed under the terms of the Creative Commons Attribution Non-Commercial License (http:/ creativecommons org/licenses/by-nc/3.0/) which permits unrestricted non-commercial use, distribution, and reproduction in any medium, provided the original work is properly cited.

Copyright $\odot 2016$ by The Korean Journal of Pancreas and Biliary Tract

서 론

담관의 천공에 의한 담즙 누출은 주로 수술이나 외상, endoscopic retrograde cholangiopancreatography (ERCP)와 같은 시술 후 발생하지만 자연적인 천공은 성인에서 매우 드 문 것으로 알려져 있다. ${ }^{1,3-6} 1882$ 년 Freeland가 담관결석에 의
한 총간관의 자연천공을 처음으로 보고한 이후 담관의 자연 천공에 대한 여러 증례가 보고 되었으나 국내에서는 아직 총 담관의 자연천공이 거의 보고되지 않고 있다. ${ }^{3}$ 최근 외상이 나 의인성 손상에 의한 담관 천공의 경우 내시경 시술과 함 께 내과적인 치료가 자리를 잡고 있지만 담관의 자연 천공에 의한 복막염은 그 증상이 다양하며, 조기 진단이 쉽지 않아 
대부분 수술을 통하여 진단과 치료가 이루어지며 내시경적 치료는 거의 시행되지 않고 있는 실정이다. ${ }^{6,7}$

저자들은 내원 2개월 전부터 시작된 복통과 난치성 복수를 주소로 내원한 환자에서 $\mathrm{ERCP}$ 를 통하여 담석증에 의한 총 담관 자연천공을 확인하고 금속스텐트 삽입술을 통하여 치 료에 성공했던 1 예를 경험하였기에 문헌고찰과 함께 보고하 는 바이다.

\section{증 례}

52세 남자가 약 2개월 전 심한 복통과 함께 복부팽만이 발생 하여 인근 병원에 내원하였고, 당시 복부 computed tomography $(\mathrm{CT})$ 에서 만성 췌장염과 함께 염증성 변화를 동반한 많은 양의 복수가 관찰되어 복강내 카테터배액술(pigtail catheter drainage)을 시행한 후 내과적 치료를 계속하던 중 복통이 지 속되고, 배액량이 줄지 않아 본원으로 전원되었다. 환자는 고 혈압, 당뇨로 투약 중이었고, 만성 췌장염의 과거력을 가지고 있었으며, 만성 신장질환으로 1년 전부터 주 3 회 혈액투석 치 료를 받고 있었다. 내원 당시 의식은 명료하였고 체온 $36.5^{\circ} \mathrm{C}$, 맥박 80 회/분, 호흡 14 회/분, 혈압은 $150 / 80 \mathrm{mmHg}$ 였다. 환자 는 만성 병색을 보였고 공막에 황달은 없었으며, 신체 검진에 서 심와부 및 하복부에 압통이 있었고 간이나 비장 종대는 없 었으며, 왼쪽 하복부에 배액 중인 카테터가 관찰되었다. 혈액 검사에서 백혈구 $12,100 / \mathrm{mm}^{3}$, 혈색소 $8.2 \mathrm{~g} / \mathrm{dL}$, 혈소판 $403,000 / \mathrm{mm}^{3}$ 였다. 일반화학검사에서 AST $22 \mathrm{IU} / \mathrm{L}$, ALT 46 IU/L, ALP 467 IU/L, gamma glutamyl transpeptidase (GGT)
$251 \mathrm{IU} / \mathrm{L}$, 총 빌리루빈 $0.3 \mathrm{mg} / \mathrm{dL}$, 아밀라아제 $43 \mathrm{IU} / \mathrm{L}$, 리파 아제 $63.9 \mathrm{IU} / \mathrm{L}$ 였다. 복부 전산화단층촬영 $(\mathrm{CT})$ 에서 간내담관 의 확장과 함께 담도 내에 공기 음영이 관찰되었지만, 총담관 의 확장이나 담석을 의심할 만한 고밀도 병변은 보이지 않았 다. 복수는 이전보다 감소되었으나 복강 내에 많은 중격이 형 성되어 있었고 췌장의 석회화 및 췌관의 확장, 확장된 담낭이 보였다(Fig. 1). 진단적 복수 천자를 시행한 결과 복수에서 총 빌리루빈이 $14.3 \mathrm{mg} / \mathrm{dL}$ 로 증가되어 있어 복강 내로 담즙의 누 출이 의심되었다. 이에 내시경역행담췌관조영술(ERCP)을 시 행한 결과 총담관 중간부위에 경계가 불분명한 $12 \times 22 \mathrm{~mm}$ 크기의 음영결손이 관찰되며, 이 부위에서 담관 밖으로 많은 양의 조영제 누출이 관찰되는데, 누출부위가 비교적 크며, 누 출된 조영제는 일정한 $5 \mathrm{~mm}$ 직경의 명확한 경계를 가지고 약 $5 \mathrm{~cm}$ 정도 오른쪽으로 진행하다가 직경이 갑자기 넓어져 조영 양상이 마치 장 내강의 형태를 보이고 있었다(Fig. 2). 우선 내 시경 유두괄약근절개술(endoscopic sphincterotomy, EST) 후 domia basket을 이용하여 한 개의 담석을 배출시킨 후, 내시경 경비담관배액술(endoscopic nasobiliary drainage, ENBD)을 시행하고 시술을 마쳤다. 다음 날 총담관으로부터 누공이 복 강 또는 장관으로 연결되었는지를 감별하기 위해 $\mathrm{ENBD}$ 카테 터에 조영제를 주사한 직후 복부 CT를 촬영한 결과 common bile duct (CBD)에 주입된 조영제는 복강 내로 누출된 후 복강 내로 퍼지지 않고 중격들에 의해 형성된 통로를 따라서 경피 적 도관이 삽입되어 있는 하복부까지 이어져 있었다(Fig. 2). 내시경적 치료를 위해 내원 9일째 $\mathrm{ERCP}$ 를 시행하였고, 바스 켓과 풍선도자를 이용하여 많은 결석을 배출시켰으며, 조직
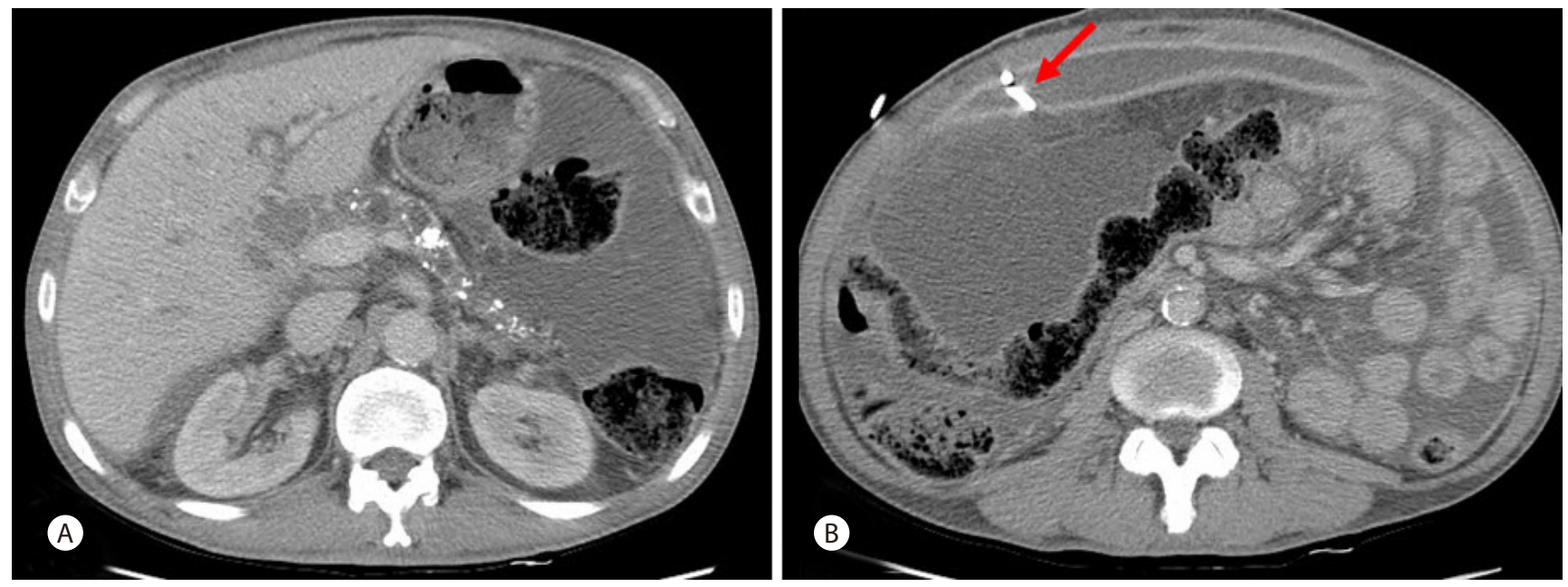

Fig. 1. Abdominal computed tomography findings. (A) Ascites with mild intrahepatic bile duct dilatation, marked pancreatic duct dilatation with calcification. (B) Percutaneous pigtail catheter drainage (arrow). 

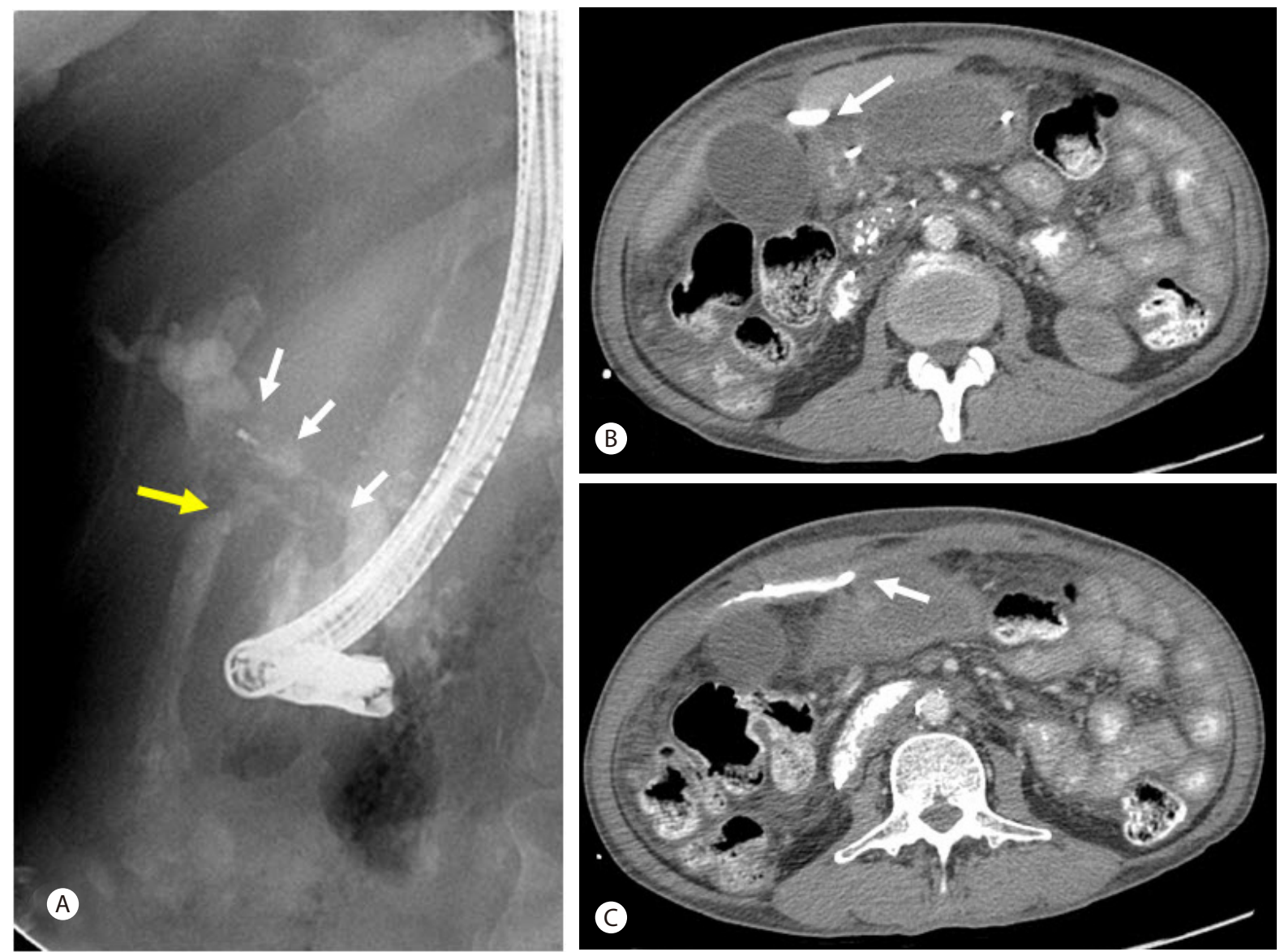

Fig. 2. (A) ERCP showed large amorphous filling defects in mid CBD (white arrows) and leakage of contrast media from mid CBD. (B, C) Abdominal computed tomography after ERCP showed contrast media in the abdominal cavity. ERCP, endoscopic retrograde cholangiopancreatography; CBD, common bile duct.
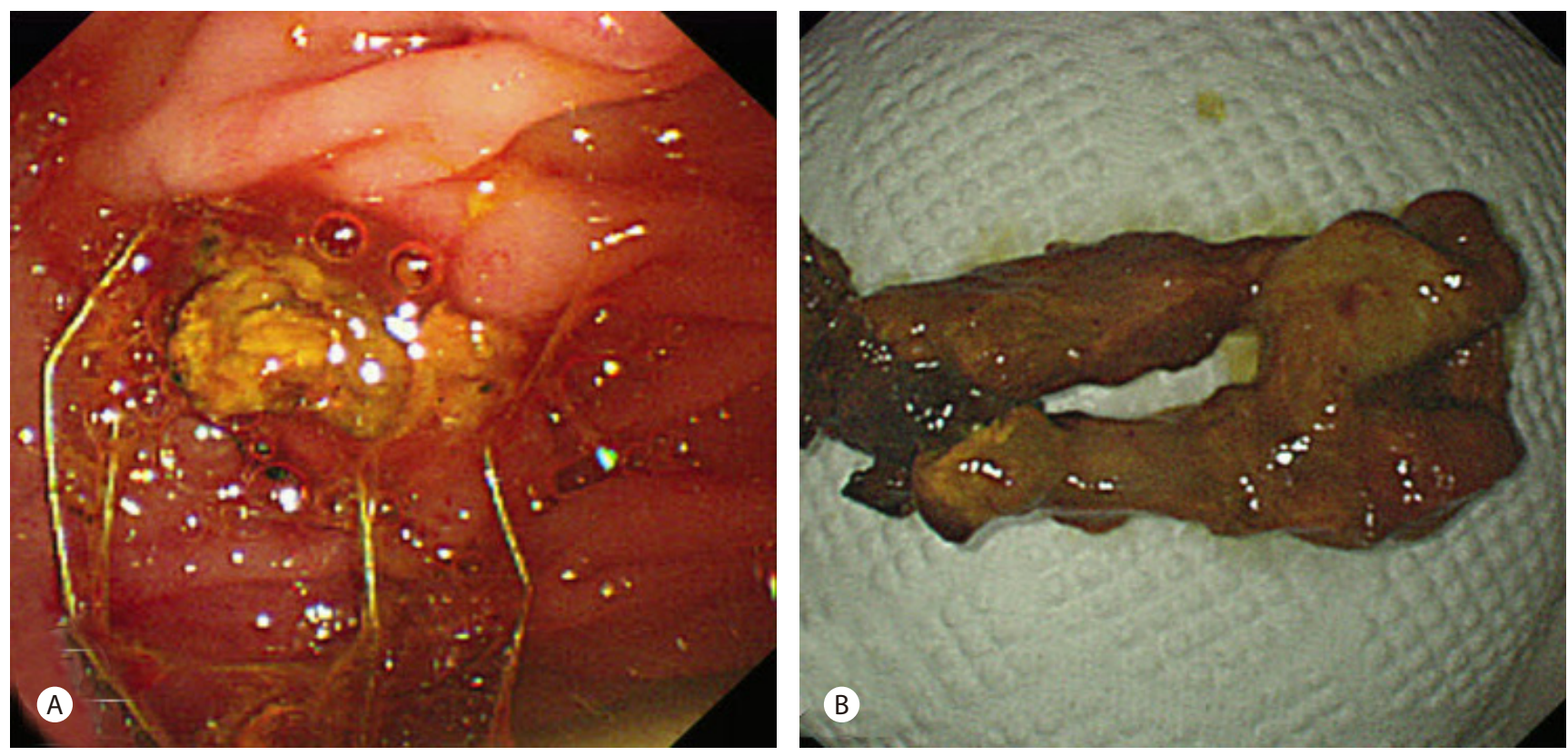

Fig. 3. (A) CBD stones were extracted by basket. (B) Mixed stone and necrotic debris. 
덩어리로 보이는 이물도 함께 배출되었다(Fig. 3). 배출된 조직 을 임상병리과에 의뢰하여 확인한 결과 담석성분 이외 특이소 견은 보이지 않았다. 두 차례의 $\mathrm{ERCP}$ 를 통해 담석이 모두 제 거되자 총담관에 플라스틱스텐트 $(7 \mathrm{Fr})$ 를 삽입한 후 시술을 마쳤다. 그러나 복강으로부터 도관 배액량(pigtail catheter drainage)은 감소되지 않아 5일 후 다시 $\mathrm{ERCP}$ 를 통하여 길이 $7 \mathrm{~cm}$, 직경 $10 \mathrm{~mm}$ 의 완전 피막형 자가팽창성 금속스텐트 (Hercules DH Biliary stent [Double Covered]; ComVi; S \& G BIOTECH INC., Seongnam, Korea)를 총담관 내에 삽입한 후 시술을 마쳤다(Fig. 4). 시술 다음 날 복강내 카테터배액량은 현저하게 감소되기 시작하였고 5일 후에는 더 이상 배액되지 않아 경피적 배액카테터를 제거하였다. 환자는 증상의 호전과 함께 체중이 증가하기 시작하여 퇴원하였고, 6주 후 금속스텐 트를 성공적으로 제거하였고, 담도조영술을 시행한 결과 총담 관에서 조영제의 누출이 더 이상 없음을 확인하였다(Fig. 5).

\section{고 찰}

성인에서 담관의 천공은 수술이나 내시경역행담도조영술 (ERCP) 등의 시술 중 담관 손상에 의해 주로 발생하며, 자연 적으로 발생하는 천공은 매우 드문 것으로 알려져 있다. ${ }^{1}$
그리고 자연적인 담즙누출에 의한 복막염은 대부분 담낭 의 천공에 의해서 발생되는데, 1912 년 McWilliams 등 ${ }^{2}$ 의 보 고에 의하면 담도계의 자연 천공으로 확인된 114 증례 중 4 명 이 총담관 천공, 1 명이 총간관 천공이었고 나머지는 모두 담 낭천공이었다. ${ }^{2}$

그 동안 알려진 담관 자연 천공의 가장 흔한 위치는 총담관 이며, 다음으로 총간관, 간내담관에 발생하는 것으로 알려져 있으나 국내에서는 지금까지 발표된 두 증례에서 우측간내 담관의 천공이었고 총담관의 천공은 1 예뿐이었다. ${ }^{1-3}$ 담관의 자연 천공의 원인은 여러 가지 기전들이 제시되고 있는데, 담도의 기계적 폐쇄로 인한 담도내 압력 상승, 감돈된 담석 의 압력 때문에 발생하는 담도의 미란, 감염에 의한 담도벽 의 약화, 혈전증에 의한 담도 벽의 궤사, 담도 안의 게실 등이 있다. ${ }^{5}$

본 증례의 경우 담도 내에 감돈되었던 많은 양의 결석들과 배출된 궤사 조직으로 미루어 보아 총담관 담석으로 인한 담 도 폐쇄 그리고 담관 내의 압력 상승 및 담도 벽의 궤사 등이 천공의 원인으로 추정된다.

담관 천공의 임상 양상은 다양하고 급성 복증의 증상을 보 이더라도 빈도수가 매우 낮은 담관의 자연 천공을 의심하기 가 쉽지 않기 때문에 수술 전 정확한 조기 진단이 어렵다. 이
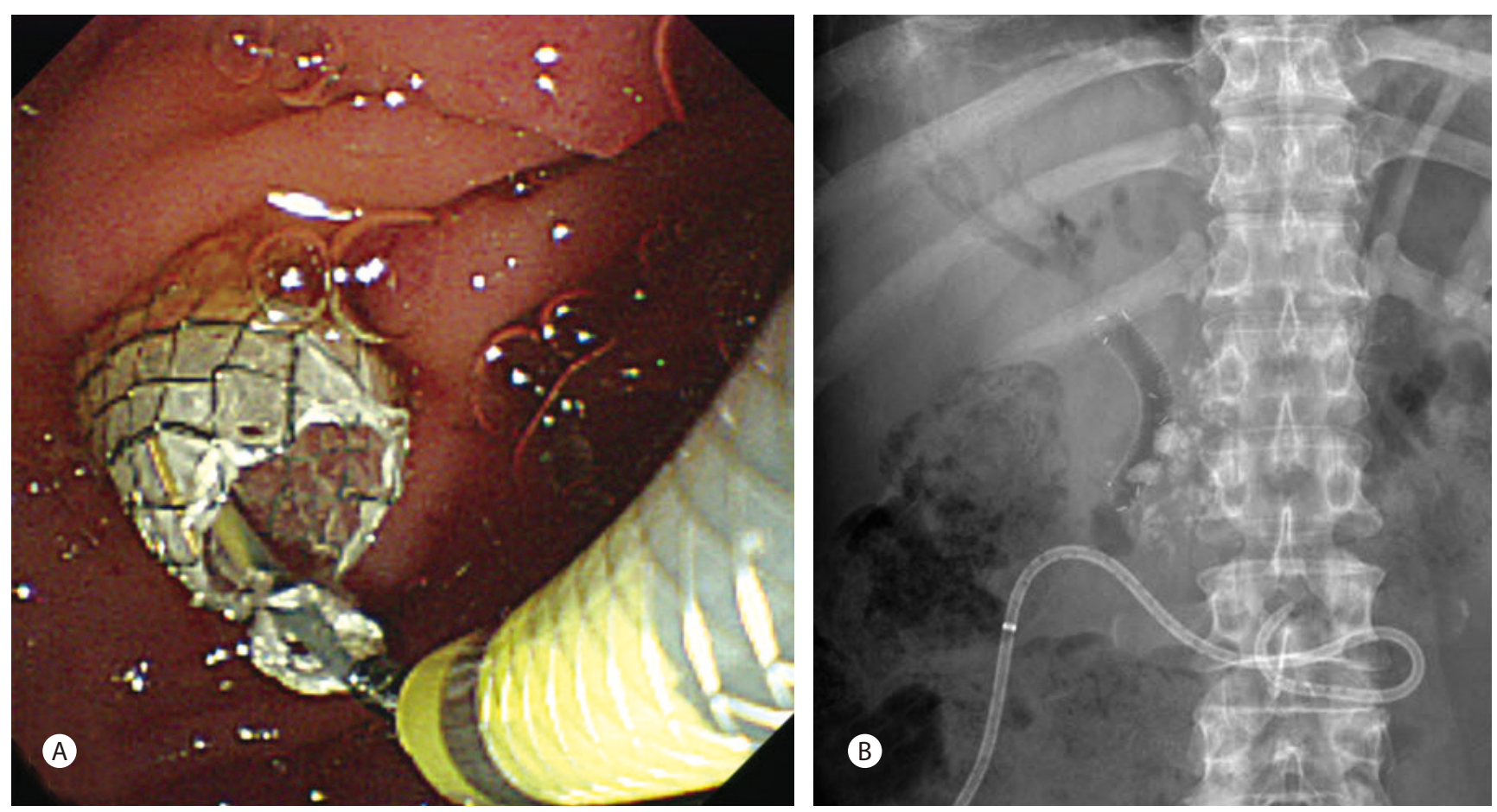

Fig. 4. Fully covered self expandable metal stent was placed in the CBD . (A) Duodenoscopy, (B) Fluoroscopy. 


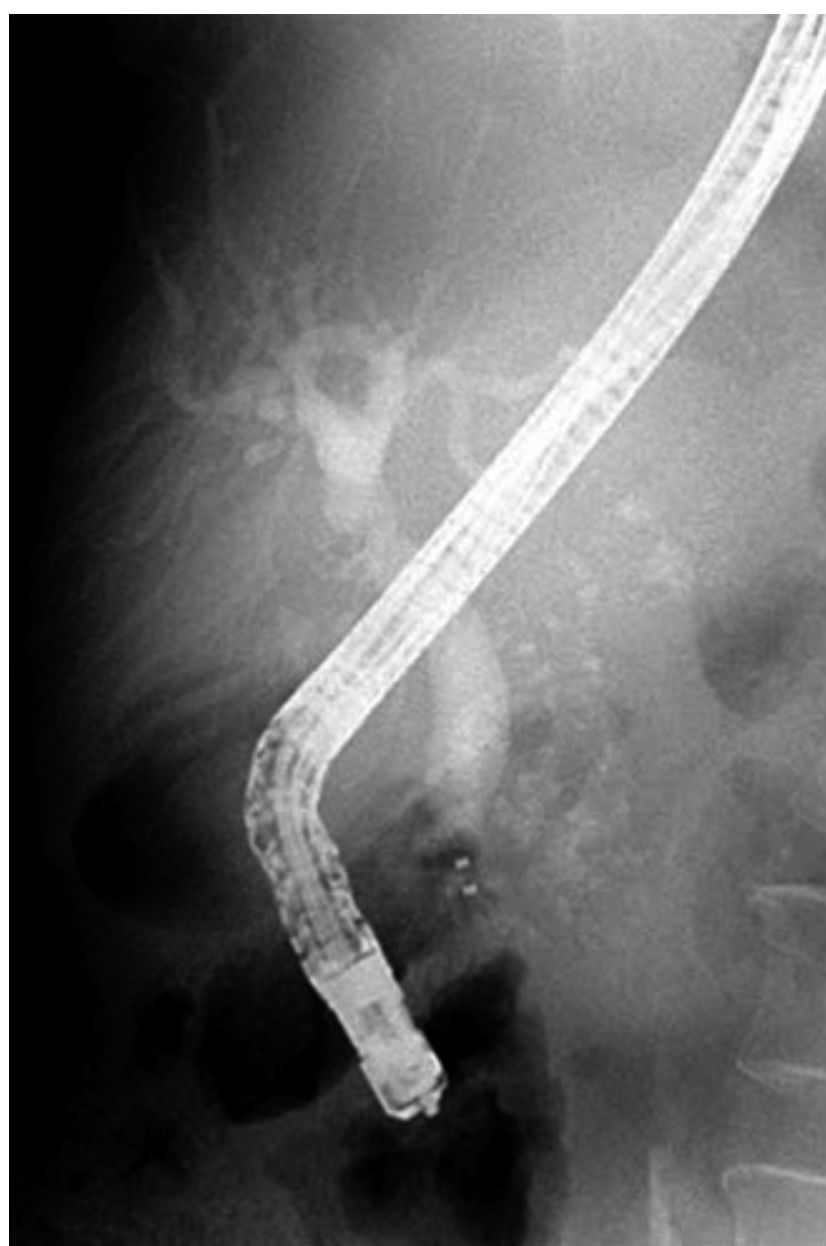

Fig. 5. Endoscopic retrograde cholangiopancreatography revealed no more leakage of contrast media.

로 인하여 담관의 자연천공의 경우 예후가 매우 불량하여, 기저질환에 따라 사망률이 $30-50 \%$ 에 이르는 것으로 알려져 있다. ${ }^{8}$

사망률을 줄이기 위해서는 조기에 정확한 진단을 통하여 적절히 치료하는 것이 중요한데, 우선 복부 초음파나 CT에 서 담관 주위에 복수나 체액의 저류가 보일 때 천공을 의심 해 볼 수 있으며 간담도 신티그래피(hepatobiliary scintigraphy)나 ERCP를 통하여 동위원소나 조영제가 담도 밖으로 새는 것을 확인할 때 진단할 수 있다. ${ }^{9,10}$

담관 자연천공에 대한 치료는 주로 T-tube 등을 이용한 담 즙배액술과 복막배액술을 시행하는 수술이었다. ${ }^{11}$ 하지만 $\mathrm{ERCP}$ 나 수술 후 발생한 담관 천공에 대하여 내과적 치료와 함께 내시경적 담즙배액술 또는 경피적 담즙배액술이 널리 사용됨에 따라 담관의 자연천공에 대해서도 내시경적 치료
가 시도되고 있다. Barnes 등 ${ }^{12}$ 은 담석을 동반한 담관의 자연 천공에 대하여 $\mathrm{ERCP}$ 를 통한 담석의 제거와 스텐트삽입술을 통하여 치료에 성공하였고, 국내의 Yoo 등 도 총담관의 자연 천공에 대하여 내시경 유두괄약근절개술(EST)와 내시경 경 비담관배액술(ENBD)을 시행하여 환자 증상을 호전시켰던 증례를 보고하였다.

본 증례는 기존에 보고되었던 증례와 달리 내원 2개월 전 이미 담관의 자발적 천공과 함께 복막염이 발생하였는데, 담 관의 배액을 위한 적절한 조치 없이 복강내 카테터배액술 (pigtail catheter drainage)과 내과적 치료만으로 2개월 동안 환자 상태가 유지되었다. 이는 초기 담즙성 복막염이 발생했 을 때 복강내 담즙과 염증성 체액의 배액과 항생제의 치료로 패혈증으로 진행되지 않았고, 이후 복강내 격막(septum)들 이 형성되어 담즙이 복강 내로 퍼지지 않고 하복부로 흘러나 올 수 있는 통로가 만들어졌기 때문으로 추정된다. 하지만 담석이 담관을 완전히 막고 있었기 때문에 담즙 천공된 부위 를 통하여 지속적으로 누출되어 천공부위가 누공을 형성하 면서 매우 커져 있었던 것도 특이했던 점이다. 이와 같은 이 유 때문에 EST를 시행하고 담석을 제거한 후 ENBD 및 $7 \mathrm{Fr}$ 의 플라스틱스텐트를 총담관 내에 삽입하였지만 경피적 복 강내 담즙 배액량이 감소하지 않았다. 이에 완전피막형 자가 팽창형 금속스텐트(fully covered self expandable metal stent, CESMS)를 삽입하여 천공부위를 완전히 막은 후에야 복강으로의 담즙누출을 막을 수 있었다. 금속피막형 스텐트 (CESMS)는 1989년 담도계 폐쇄의 치료에 소개된 이후 현재 는 악성 담도협착의 보존적 치료를 위해 일반적으로 시행되 고 있다. ${ }^{13}$ 수술 등의 의인성 담도계 천공에서도 내시경적 치 료가 수술을 대신하여 사용되고 있는데, 대개는 ENBD 또는 플라스틱스텐트를 주로 사용하고 있다. ${ }^{14}$ 만성 췌장염, 간 이 식 수술 후의 해부학적 협착, 염증성 질환들, 담도 결석 등의 담도의 양성 협착의 치료를 위해 금속스텐트를 이용한 치료 가 보고되고 있는데 ${ }^{15}$ 스텐트의 이동, 스텐트내 조직의 증식 등이 발생할 수 있는 단점들이 문제로 지적되고 있으며, 이 를 극복할 수 있는 기능을 가진 새로운 방면으로의 연구와 개발이 더 필요한 실정이다. 하지만 담도의 자연 천공에 대 해서 금속스텐트를 이용하여 치료한 사례는 아직 보고되지 않아 앞으로 더 많은 증례와 경험이 필요할 것으로 보인다. 


\section{요 약}

총담관의 자발적 천공은 흔하지 않으며, 이에 대해 충분한 연구와 경험이 부족한 상태이다. 본 저자들은 원인을 알 수 없는 복통과 난치성 복수를 호소하는 환자에서 총담관의 자 발적 천공을 진단하고, 내시경역행담췌관조영술을 통한 완 전피막형 자가팽창형 금속스텐트의 삽입술과 보존적 치료를 통하여 치료에 성공했던 증례를 경험하였기에 보고한다.

\section{국문 색인: 자발적 담즙 누출, 총담관 결석, 내시경적 역행성} 담도 췌관조영술, 담관 천공, 복수

\section{Conflicts of Interest}

The author has no conflicts to disclose.

\section{REFERENCES}

1. Paladugu R, Rau A, Schein M, Wise L. Spontaneous perforation of the hepatic duct in adults. Dig Surg 1998;15:417-420.

2. McWilliams CA. Acute spontaneous perforation of the biliary system into the free peritoneal cavity: a report of six cases from the Presbyterian Hospital of New York and 108 cases from the literature. Ann Surg 1912; 55:235-263.

3. Roe IH, Bae SK, Kim JT. A case of spontaneous perforation of the right intrahepatic duct - an ERCP diagnosis. Korean J Gastrointest Endosc 1992;12:87-90.

4. Park DS, Jung BJ, Ahn KS, et al. A case of spontaneous perforation of the right intrahepatic duct diagnosed by ERCP. Korean J Pancreas Bili- ary Tract 1996;1:284-286.

5. Kerstein MD, McSwain NE. Spontaneous rupture of the common bile duct. Am J Gastroenterol 1985;80:469-471.

6. Yoo BK, Kim JH, Moon HJ, et al. A case of spontaneous perforation of the common bile duct associated with cholangitis. Korean J Gastroenterol 2005;45:361-364.

7. Thaggard WG, Johnson PN, Baron TH. Endoscopic management of spontaneous bile duct perforation and bile peritonitis complicating term pregnancy. Am J Gastroenterol 1995;90:2054-2055.

8. Borghese M, Caramanico L, Anelli L, De Cesare A, Farrocco G, Spallone $\mathrm{G}$. Etiopathogenetic and physiopathological considerations on biliary peritonitis. Minerva Med 1986;77:735-738.

9. Kumar R, Sriram M, Bhatnagar V, Padhy AK, Malhotra A. Spontaneous perforation of the common bile duct in infancy: role of Tc-99m mebrofenin hepatobiliary imaging. Clin Nucl Med 1999;24:847-848.

10. Goldberg D, Rosenfeld D, Underberg-Davis S. Spontaneous biliary perforation: biloma resembling a small bowel duplication cyst. J Pediatr Gastroenterol Nutr 2000;31:201-203.

11. Evans K, Marsden N, Desai A. Spontaneous perforation of the bile duct in infancy and childhood: a systematic review. J Pediatr Gastroenterol Nutr 2010;50:677-681.

12. Barnes BH, Narkewicz MR, Sokol RJ. Spontaneous perforation of the bile duct in a toddler: the role of endoscopic retrograde cholangiopancreatography in diagnosis and therapy. J Pediatr Gastroenterol Nutr 2006;43:695-697.

13. Jeong S. Basic knowledge about metal stent development. Clin Endosc 2016;49:108-112.

14. Irani S, Baron TH, Law $R$, et al. Endoscopic treatment of nonstricturerelated benign biliary diseases using covered self-expandable metal stents. Endoscopy 2015;47:315-321.

15. Kwon $\mathrm{Cl}$, Ko KH, Hahm KB, Kang DH. Functional self-expandable metal stents in biliary obstruction. Clin Endosc 2013;46:515-521. 